\title{
An analysis of invasive micropapillary breast carcinoma based on hormone receptor and epidermal growth receptor 2 status
}

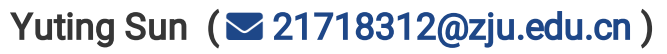 \\ Zhejiang University
}

\section{Research article}

Keywords: invasive micropapillary breast carcinoma, hormone receptor, epidermal growth receptor 2

Posted Date: October 5th, 2020

DOI: https://doi.org/10.21203/rs.3.rs-75398/v1

License: @ (i) This work is licensed under a Creative Commons Attribution 4.0 International License. Read Full License 


\section{Abstract \\ Background}

This research aimed to explore the role of combining hormone receptor (HR) with epidermal growth factor receptor 2 (Her-2) status of invasive micropapillary breast carcinoma (IMPC).

\section{Methods}

1291 IMPC patients were retrieved from the Surveillance, Epidemiology, and End Results (SEER) database of the US National Cancer Institute. The $\mathrm{X}^{2}$ test and Fisher's exact probability test were used to evaluate differences between qualitative variables. Univariate and multivariate Cox proportional hazards regressions were performed to assess the independent prognostic factors on cancer-specific survival (CSS) and overall survival (OS). The nomogram models were made to predict 3-year survival rate of IMPC using R software.

\section{Results}

Among 1291 patients, HR+/Her-2- subtype accounted for 74.7\%, while HR-/Her-2+, HR-/Her-2-, HR+/Her-2 + accounted for $4.7 \%, 4.0 \%$ and $15.6 \%$ respectively. The $\mathrm{X}^{2}$ test indicated compared to HR+/Her-2- subgroup, HR-/Her-2- or HR+/Her-2 + subtype IMPC had larger tumor size (T stage) and higher histological grade. Compared to HR+/Her-2- IMPC, HR-/Her-2and $\mathrm{HR}+/ \mathrm{Her}-2$ + subtypes were more likely to receive mastectomy than conserving surgery. Furthermore, $\mathrm{HR}+/ \mathrm{Her}-2-$ IMPC had more projections to receive chemotherapy and was less likely to receive radiotherapy compared with HR-/Her2- subtype. Survival analysis suggested that HR-/Her-2- IMPC had the worst OS and CSS.

\section{Conclusion}

This population-based study provided evidence that HR-/Her-2- IMPC accounted the smallest part of four subtypes, but were more likely to have larger tumor size and more advanced histological grade. Furthermore, HR+/Her-2- IMPC had most unfavorable prognosis among four subtypes.

\section{Background}

IMPC was a rare special type of breast cancer, ${ }^{1}$ composed of small, hollow or morula-like clusters of cancer cells, surrounded by clear stromal spaces. ${ }^{2}$ Several studies have illuminated that IMPC had higher rates of positive axillary lymph nodes, lager tumor size, more advanced histological grade than IDC. ${ }^{345}$ Despite its highly aggressive clinical performance, a study found that IMPC had a better long-term survival outcome comparing with IDC. ${ }^{5}$ A meta-analyses found that IMPC patients were more likely to have local regional recurrence(LRR) than IDC, but the OS and CSS were not significantly different between IMPC and IDC. ${ }^{7}$ A population based study showed that hormone positive IMPC had a better survival. ${ }^{8}$ And prior studies have compared prognosis based on HR or Her-2 status between IMPC and IDC. ${ }^{9}$ However, they did not combine these two factors together to analyze its impact on survival of IMPC. Here, in this study, we divided IMPC into four molecular subtypes according to hormone receptor (including estrogen receptor (ER) and progesterone receptor (PR)) and epidermal growth factor receptor 2(Her-2) status to analyze the features of IMPC in a more reasonable way.

\section{Methods}




\section{Data collection}

The SEER ${ }^{\star}$ Stat (version 8.3.5) Case Listing session was used to get 1291 cases of IMPC (8507/3: Ductal carcinoma, micropapillary). In consideration of the information on breast cancer molecular subtype was not available until 2010, we selected IMPC patients from 2010 to 2015 from the Surveillance, Epidemiology, and End Results(SEER), version 8.3.5. The deadline for follow-up time was November 2016. The morphological classification of breast cancer was Ductal carcinoma, micropapillary according to Oncology, version 3(ICD-0-3). All patients included in this study were female, and patients with unknown subtype, ethnicity, T stage, $\mathrm{N}$ stage, $\mathrm{M}$ stage and grade were excluded from this study.

\section{Clinicopathological factors}

In this study, we used the 7th AJCC version to evaluate TNM (T: tumor size; N: axillary lymph nodes metastasis; M: distant metastasis) and stage. IMPC was classified into four molecular types according to the expression of hormone receptor(HR) and epidermal growth factor receptor 2 (HER2): HR+/Her-2-, HR-/Her-2+, HR-/HER2-, HR+/HER2+. According the criterion of SEER database, the definition of hormone receptor positive was as follows: either ER positive or PR positive, and if $1 \%$ or greater cells stained positive, the test results of ER or PR was considered positive. HER2 expression was examined by any of following ways in laboratories: fluorescence in situ hybridization (FISH), immunohistochemistry $(\mathrm{IHC})$ or chromogenic in situ hybridization (CISH). Her-2 positive meant it was amplified or overexpression in any of these three ways. Surgery type was sorted into three types: mastectomy, breast-conserving surgery, and no surgery or not recommended. And we got the permission to obtain chemotherapy and radiotherapy data of patients from the SEER.

\section{Statistical analysis}

SPSS Statistics software (version 23.0) was used to analyze the data. $X^{2}$ test was used to analyze the characteristics of IMPC. The Kaplan-Meier method was used to construct the OS and CSS of IMPC. The Cox proportional hazards regression model was used to determine the independent prognostic factors for OS and CSS. Hazard ratios (HRs) with corresponding $95 \% \mathrm{Cl}$ were used to show the effect of factors on OS and CSS. A p value of $<0.05$ was considered statistically significant. To present the prognostic factors of IMPC more clearly, we use nomogram models to show factors that have impacts on OS and CSS of IMPC.

\section{Results}

In this study, we made comparisons in four groups using $\mathrm{X}^{2}$ test: HR+/Her-2- vs. HR-/Her-2-, HR+/Her2- vs. HR+/Her-2+, HR-/Her-2 + vs. HR-/Her-2-, HR-/Her-2 + vs. HR+/Her-2+. The characteristics of four subtypes of IMPC were shown in Table 1. There were 964 (74.7\%) IMPC patients belonging to HR+/Her-2- subtype, which accounted for the largest number of population in this study. HR-/Her-2- subtype was the smallest part which accounted for only $4.0 \%$. Most patients were over 50 years old when they were diagnosed with IMPC (80.0\%). 614 of 1291 (47.6\%) IMPC patients had positive axillary lymph nodes when first diagnosis which suggested IMPC had a high ratio of lymph node invasion. A mastectomy was performed in 590 (45.7\%) patients and $642(49.7 \%)$ patients received conserving surgery. 
Table 1

Characteristics of four subtypes of IMPC patients

\begin{tabular}{|c|c|c|c|c|c|c|c|c|c|}
\hline variables & $\begin{array}{l}\mathrm{HR}+/ \\
\text { Her-2-(\%) }\end{array}$ & $\begin{array}{l}\text { HR-/ } \\
\text { Her-2+ } \\
(\%)\end{array}$ & $\begin{array}{l}\text { HR-/ } \\
\text { Her-2- } \\
(\%)\end{array}$ & $\begin{array}{l}\text { HR+/ } \\
\text { Her-2+(\%) }\end{array}$ & $N(\%)$ & $p^{1}$ & $p^{2}$ & $p^{3}$ & $p^{4}$ \\
\hline \multicolumn{10}{|l|}{ Ages } \\
\hline$<50$ & $166(17.2)$ & $14(23.0)$ & $12(23.1)$ & 66(30.8) & $258(20.0)$ & 0.297 & 0.000 & 0.987 & 0.231 \\
\hline$>=50$ & $798(82.64)$ & $47(77.0)$ & $40(76.9)$ & $148(69.2)$ & 1033(80.0) & & & & \\
\hline \multicolumn{10}{|l|}{ Ethnicity } \\
\hline black & $116(12.0)$ & 10(19.2) & 10(19.2) & $28(35.9)$ & $161(12.5)$ & 0.300 & 0.109 & 0.508 & 0.433 \\
\hline white & 738(76.6) & $36(69.2)$ & $36(69.2)$ & $172(46.2)$ & $993(76.9)$ & & & & \\
\hline others & $110(11.4)$ & $6(11.5)$ & $6(11.5)$ & 14(17.9) & 137(10.6) & & & & \\
\hline \multicolumn{10}{|l|}{ T stage } \\
\hline T1 & $571(59.2)$ & $33(54.2)$ & $19(36.5)$ & 107(57.0) & 730(56.6) & 0.004 & 0.024 & 0.109 & 0.402 \\
\hline T2-3 & $359(37.2)$ & $22(36.1)$ & $29(55.8)$ & $94(43.9)$ & $504(39.0)$ & & & & \\
\hline $\mathrm{T} 4$ & $34(3.5)$ & $6(9.8)$ & $4(7.7)$ & $13(6.1)$ & $57(4.4)$ & & & & \\
\hline \multicolumn{10}{|l|}{$\mathrm{N}$ stage } \\
\hline NO & $524(54.4)$ & $30(49.2)$ & $22(42.3)$ & $101(47.2)$ & $677(52.4)$ & 0.175 & 0.150 & 0.743 & 0.753 \\
\hline N1-2 & $373(38.7)$ & 24(39.3) & $24(46.2)$ & $94(43.9)$ & 515(39.9) & & & & \\
\hline N3 & $67(7.0)$ & $7(11.5)$ & $6(11.5)$ & 19(8.9) & $99(7.7)$ & & & & \\
\hline \multicolumn{10}{|l|}{ M stage } \\
\hline MO & $936(97.1)$ & $55(90.2)$ & 48(92.3) & 204(95.3) & 1243(96.3) & 0.054 & 0.185 & 0.751 & 0.129 \\
\hline M1 & $28(2.9)$ & $6(9.8)$ & $4(7.7)$ & $10(4.7)$ & $48(3.7)$ & & & & \\
\hline \multicolumn{10}{|l|}{ Grade } \\
\hline G 1-2 & $677(70.2)$ & $29(47.5)$ & 15(28.8) & $111(51.9)$ & $832(64.4)$ & 0.000 & 0.000 & 0.042 & 0.551 \\
\hline G 3-4 & $287(29.8)$ & $32(52.5)$ & $37(71.2)$ & $103(48.1)$ & $459(35.6)$ & & & & \\
\hline \multicolumn{10}{|l|}{ Stage } \\
\hline stage I & $435(45.1)$ & $27(44.3)$ & 16(30.8) & $83(38.8)$ & $561(43.5)$ & 0.080 & 0.000 & 0.357 & 0.252 \\
\hline stage II & $334(34.6)$ & $16(26.2)$ & $21(40.4)$ & $59(27.6)$ & $430(33.3)$ & & & & \\
\hline stage III & 167(17.3) & 12(19.7) & $11(21.2)$ & $62(29.0)$ & $252(19.5)$ & & & & \\
\hline stage IV & $28(2.9)$ & $6(9.8)$ & $4(7.7)$ & $10(4.7)$ & $48(3.7)$ & & & & \\
\hline
\end{tabular}

$p^{1}$ : HR+/Her-2-vs. HR-/Her-2-; $p^{2}$ : HR+/Her2-vs. HR+/Her-2+;

$p^{3}$ : HR-/Her-2 + vs. HR-/Her-2-; $\mathrm{p}^{4}$ : HR-/Her-2 + vs. HR+/Her-2+ 


\begin{tabular}{|c|c|c|c|c|c|c|c|c|c|}
\hline variables & $\begin{array}{l}\text { HR+/ } \\
\text { Her-2-(\%) }\end{array}$ & $\begin{array}{l}\text { HR-I } \\
\text { Her-2+ } \\
(\%)\end{array}$ & $\begin{array}{l}\text { HR-/ } \\
\text { Her-2- } \\
(\%)\end{array}$ & $\begin{array}{l}\text { HR+/ } \\
\text { Her-2+(\%) }\end{array}$ & $N(\%)$ & $p^{1}$ & $p^{2}$ & $p^{3}$ & $p^{4}$ \\
\hline no/unknown & $38(3.9)$ & $4(6.6)$ & $3(5.8)$ & $14(6.5)$ & $59(4.6)$ & 0.065 & 0.006 & 0.985 & 0.730 \\
\hline mastectomy & $414(42.9)$ & $35(57.4)$ & $30(54.5)$ & 111(51.9) & $590(45.7)$ & & & & \\
\hline $\begin{array}{l}\text { conserving } \\
\text { surgery }\end{array}$ & $512(53.1)$ & $22(36.1)$ & 19(40.0) & $89(41.6)$ & $642(49.7)$ & & & & \\
\hline \multicolumn{10}{|l|}{ Radiotherapy } \\
\hline no/unknown & $545(56.5)$ & $32(52.5)$ & $23(44.3)$ & $99(46.3)$ & $699(54.1)$ & 0.082 & 0.006 & 0.383 & 0.393 \\
\hline yes & $419(43.5)$ & $29(47.5)$ & $29(55.8)$ & $115(53.7)$ & $592(45.9)$ & & & & \\
\hline \multicolumn{10}{|l|}{ Chemotherapy } \\
\hline no/unknown & $389(40.4)$ & $53(86.9)$ & $34(65.4)$ & $166(77.6)$ & $642(49.7)$ & 0.000 & 0.000 & 0.007 & 0.111 \\
\hline yes & $575(59.6)$ & $8(13.1)$ & 18(34.6) & $48(22.4)$ & $649(50.3)$ & & & & \\
\hline \multicolumn{10}{|c|}{$p^{1}:$ HR+/Her-2-vs. HR-/Her-2; $p^{2}:$ HR+/Her2-vs. HR+/Her-2+; } \\
\hline \multicolumn{10}{|c|}{$p^{3}:$ HR-/Her-2 + vs. HR-/Her-2; p ${ }^{4}:$ HR-/Her-2+vs. HR+/Her-2+ } \\
\hline
\end{tabular}

\section{Clinical Pathological features}

Comparing with HR-/Her-2- subgroups, HR+/Her-2- and HR-/Her-2 + IMPC patients had a higher proportion of Grade I (well differentiated) or Grade II (moderately differentiated) (HR-/Her2- vs. HR+/Her-2-, p<0.001; HR-/Her-2- vs. HR+/Her-2+, p = 0.042). Patients with HR+/Her-2- features were more likely to receive chemotherapy while HR-/Her- $2+$ groups had less proportions of receiving chemotherapy compared with HR-/Her-2- group (HR+/Her2- vs. HR-/Her-2-, p $<0.001 ; \mathrm{HR}-/ \mathrm{Her}-2+$ vs. HR-/Her-2+, $\mathrm{p}<0.001)$. Furthermore, comparing to HR+/Her-2- IMPC patients, patients with HR+/Her- + status had larger tumor size $(p=0.024)$, worse histological grade $(p<0.001)$ and were less likely to accept chemotherapy $(p<0.001)$ and surgery treatments $(p=0.006)$.

In addition, we made further analysis of the two surgery types (data showed in Table 2), and we found that comparing with HR+/Her-2- subtype, HR+/Her-2 + and HR-/Her-2- IMPC patients were more likely to receive mastectomy than conserving surgery.

Table 2

Comparison of two surgery types based on four subtypes of IMPC

\begin{tabular}{|c|c|c|c|c|c|c|c|c|c|}
\hline $\begin{array}{l}\text { Surgery } \\
\text { type }\end{array}$ & $\begin{array}{l}\text { HR+/ } \\
\text { Her-2-(\%) }\end{array}$ & $\begin{array}{l}\text { HR-/ } \\
\text { Her-2+(\%) }\end{array}$ & $\begin{array}{l}\text { HR-/ } \\
\text { Her-2-(\%) }\end{array}$ & $\begin{array}{l}\text { HR+/ } \\
\text { Her-2+(\%) }\end{array}$ & $N(\%)$ & $p^{1}$ & $p^{2}$ & $p^{3}$ & $p^{4}$ \\
\hline Mastectomy & $414(44.7)$ & $35(61.4)$ & $30(61.2)$ & $111(55.5)$ & $590(47.9)$ & 0.024 & 0.006 & 0.985 & 0.427 \\
\hline $\begin{array}{l}\text { Conserving } \\
\text { surgery }\end{array}$ & $512(55.3)$ & $22(38.6)$ & 19(38.8) & $89(44.5)$ & $642(52.1)$ & & & & \\
\hline \multicolumn{10}{|c|}{$p^{1}$ : HR+/Her-2- vs. HR-/Her-2-; ${ }^{2}$ : HR+/Her2-vs. HR+/Her-2+; } \\
\hline \multicolumn{10}{|c|}{ 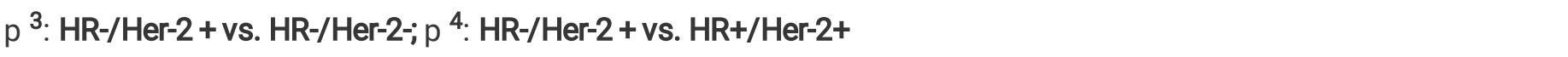 } \\
\hline
\end{tabular}




\section{Potential prognostic factors of OS and CSS}

The 3-year OS of HR+/Her-2-, HR-/Her-2+, HR-/Her-2- and HR+/Her-2 + were 93.2\%, 97.9\%, 70.9\% and 88.3 respectively. On univariate analysis, ethnicity, subtype, histological grade, tumor size, distant metastasis, surgery type, chemotherapy and radiotherapy were found to be prognostic factors for OS of IMPC. For CSS, the prognostic factors were ethnicity, subtype, histological grade, $\mathrm{T}$ stage, $\mathrm{N}$ stage, $\mathrm{M}$ stage, surgery type and radiotherapy. Univariate analysis data was shown in Table 3. We also conducted two nomogram models to predict prognostic factors of invasive micropapillary breast carcinoma's 3-year survival rate (OS, Fig. 1, supplementary Fig. 1; CSS: Fig. 2, supplementary Fig. 2). The nomogram plot showed the calibration was ideal. 
Table 3

univariate analysis for IMPC patients

\begin{tabular}{|c|c|c|c|c|}
\hline variables & os & & css & \\
\hline & $\mathrm{HR}(\mathrm{Cl} 95 \%)$ & $P$ value & $\mathrm{HR}$ (Cl 95\%) & $p$ value \\
\hline \multicolumn{5}{|l|}{ Age } \\
\hline$<50$ & 1 & - & 1 & - \\
\hline$>=50$ & $1.578(0.811-3.072)$ & 0.179 & $1.226(0.510-2.947)$ & 0.648 \\
\hline \multicolumn{5}{|l|}{ Ethnicity } \\
\hline black & 1 & - & 1 & - \\
\hline white & $0.560(0.321-0.977)$ & 0.041 & $0.372(0.177-0.783)$ & 0.009 \\
\hline other & $0.297(0.099-0.890)$ & 0.030 & $0.350(0.096-1.273)$ & 0.111 \\
\hline \multicolumn{5}{|l|}{ Grade } \\
\hline G 1-2 & 1 & - & 1 & - \\
\hline G 3-4 & $1.700(1.081-2.675)$ & 0.022 & $2.599(1.339-5.042)$ & 0.005 \\
\hline \multicolumn{5}{|l|}{ T stage } \\
\hline T1 & 1 & - & 1 & \\
\hline T2-3 & $1.460(0.887-2.402)$ & 0.136 & $2.750(1.226-6.170)$ & 0.014 \\
\hline $\mathrm{T} 4$ & $7.421(3.868-14.238)$ & 0.000 & $19.917(7.687-47.048)$ & 0.000 \\
\hline \multicolumn{5}{|l|}{ N stage } \\
\hline No & 1 & - & 1 & - \\
\hline $\mathrm{N} 1-2$ & $1.414(0.869-2.301)$ & 0.163 & $2.836(1.291-6.228)$ & 0.009 \\
\hline N3 & $1.869(0.916-3.815)$ & 0.086 & $4.349(1.618-11.691)$ & 0.004 \\
\hline \multicolumn{5}{|l|}{ M stage } \\
\hline MO & 1 & & 1 & \\
\hline M1 & $10.216(5.846-17.864)$ & 0.000 & $18.807(9.318-37.961)$ & 0.000 \\
\hline \multicolumn{5}{|l|}{ Subtype } \\
\hline $\mathrm{HR}+/ \mathrm{Her}-2-$ & 1 & - & 1 & - \\
\hline HR-/Her-2+ & $0.618(0.150-2.544)$ & 0.505 & $0.611(0.083-4.519)$ & 0.629 \\
\hline HR-/Her-2- & $5.110(2.651-9.850)$ & 0.000 & $5.896(2.407-14.443)$ & 0.000 \\
\hline $\mathrm{HR}+/ \mathrm{Her}-2+$ & $1.481(0.816-2.687)$ & 0.197 & $1.087(0.414-2.850)$ & 0.866 \\
\hline \multicolumn{5}{|l|}{ Surgery type } \\
\hline no surgery & 1 & - & 1 & - \\
\hline mastectomy & $0.109(0.061-0.196)$ & 0.000 & $0.122(0.056-0.266)$ & 0.000 \\
\hline
\end{tabular}




\begin{tabular}{|lllll|}
\hline variables & OS & \multicolumn{2}{l|}{ CSS } \\
\hline Conserving sugary & $0.087(0.048-0.157)$ & 0.000 & $0.049(0.019-0.125)$ & 0.000 \\
\hline Chemotherapy & & & & \\
\hline no/unknown & 1 & - & 1 & - \\
\hline yes & $1.908(1.195-3.048)$ & 0.007 & $1.172(0.609-2.253)$ & 0.635 \\
\hline Radiotherapy & & & & - \\
\hline yes & 1 & - & 1 & 0.003 \\
\hline no/unknown & $4.712(2.744-8.094)$ & 0.000 & $2.851(1.425-5.703)$ & \\
\hline Cl = 95\% confidence interval; HR = hazard ratio & & & \\
\hline
\end{tabular}

Multivariate variate analysis revealed that histological grade, tumor size, distant metastasis, subtype, surgery type, and radiotherapy were prognostic factors for OS and CSS. Though it has been determined IMPC's aggressive behavior related to its high proportions of axillary lymph node metastases, nodal stage was not a prognostic factor on OS and CSS in this study. Multivariate analysis data was shown in Table 4. 
Table 4

multivariate analysis for IMPC patients

\begin{tabular}{|c|c|c|c|c|}
\hline Variables & OS & & css & \\
\hline & $\mathrm{HR}(95 \% \mathrm{Cl})$ & $p$ value & $\mathrm{HR}(95 \% \mathrm{Cl})$ & $p$ value \\
\hline \multicolumn{5}{|l|}{ Ethnicity } \\
\hline black & 1 & - & 1 & - \\
\hline white & $0.702(0.393-1.254)$ & 0.231 & $0.508(0.232-1.113)$ & 0.090 \\
\hline others & $0.375(0.124-1.135)$ & 0.083 & $0.512(0.136-1.926)$ & 0.322 \\
\hline \multicolumn{5}{|l|}{ Grade } \\
\hline G 1-2 & 1 & - & 1 & - \\
\hline G 3-4 & $1.844(1.160-2.932)$ & 0.010 & $2.050(1.046-4.020)$ & 0.037 \\
\hline \multicolumn{5}{|l|}{ T stage } \\
\hline $\mathrm{T} 1$ & 1 & - & 1 & - \\
\hline T2-3 & $1.723(1.025-2.895)$ & 0.040 & $2.358(1.039-5.351)$ & 0.040 \\
\hline $\mathrm{T} 4$ & $4.840(2.032-11.528)$ & 0.000 & $5.682(1.862-17.339)$ & 0.002 \\
\hline \multicolumn{5}{|l|}{ N stage } \\
\hline NO & - & - & 1 & - \\
\hline $\mathrm{N} 1-2$ & - & - & $1.560(0.648-3.759)$ & 0.321 \\
\hline N3 & - & - & $1.287(0.400-4.143)$ & 0.673 \\
\hline \multicolumn{5}{|l|}{ M stage } \\
\hline MO & 1 & - & 1 & - \\
\hline M1 & $2.743(1.240-6.066)$ & 0.013 & 7.519(3.083-18.337) & 0.000 \\
\hline \multicolumn{5}{|l|}{ Subtype } \\
\hline $\mathrm{HR}+/$ Her-2- & 1 & - & 1 & - \\
\hline HR-/Her-2+ & $1.173(0.274-5.020)$ & 0.830 & $0.509(0.067-3.883)$ & 0.515 \\
\hline HR-/Her-2- & $7.625(3.720-15.630)$ & 0.000 & $5.511(1.770-15.936)$ & 0.003 \\
\hline $\mathrm{HR}+/ \mathrm{Her}-2+$ & $2.172(1.168-4.086)$ & 0.015 & $0.961(0.347-2.657)$ & 0.938 \\
\hline \multicolumn{5}{|l|}{ Surgery type } \\
\hline no surgery & 1 & - & 1 & - \\
\hline mastectomy & $0.298(0.143-0.621)$ & 0.001 & $0.453(0.163-1.261)$ & 0.130 \\
\hline Conserving surgery & $0.482(0.210-1.107)$ & 0.085 & $0.410(0.109-1.548)$ & 0.188 \\
\hline \multicolumn{5}{|l|}{ Chemotherapy } \\
\hline yes & 1 & - & - & - \\
\hline
\end{tabular}




\begin{tabular}{|lllll|}
\hline Variables & OS & CSS & \\
\hline no/unknown & $2.540(1.508-4.279)$ & 0.000 & - & - \\
\hline Radiotherapy & & - & 1 & - \\
\hline yes & 1 & - & $3.234(1.601-6.531)$ & 0.001 \\
\hline no/unknown & $4.312(2.369-7.851)$ & 0.000 & & \\
\hline Cl=95\% confidence interval; HR = hazard ratio & & & \\
\hline
\end{tabular}

\section{HR-/Her-2- subtype IMPC had the worst prognosis}

Among the four subtypes, HR-/Her-2- subtype IMPC had the worst OS $(p<0.001)$ and CSS $(p<0.001)(F i g .3,4)$.

\section{Discussion}

Breast cancer could be divided into four subtypes according to hormone status, epidermal growth factor 2 status and Ki67 expression level. In recent years, it has been widely accepted that treatments for breast cancer should be based on different molecular subtypes. Most studies' explorations were based on nonspecific breast cancer. But IMPC was a special and rare type of breast cancer, which behaviored more aggressively than invasive ductal breast carcinoma. Previous clinical studies proved that breast cancer with ER and PR positive status was associated with better OS and CSS. 51011 Several studies suggested that molecular subtype of breast cancer provided additional prognostic information regarding patient outcomes. ${ }^{12} 1113$ A population based study showed that hormone positive IMPC had a better survival. ${ }^{8}$ Therefore, in this study we used breast cancer molecular type to analyze the impact of combination HR with Her-2 status on IMPC. Our results indicated that HR-/Her-2- subtype had the most unfavorable prognosis.

As was mentioned above, hormone positive status was associated with better OS and CSS, many studies separately analyzed the effects of hormone receptor and HER2 expression status on IMPC. ${ }^{9}$ In fact, many previous research has proven that molecular subtype can affect prognosis on breast carcinoma. ${ }^{12} 1415$ Here in this study, multivariate analysis indicated that only HR-/Her-2- subtype had a worse prognosis on OS and CSS comparing to HR+/HER2- subtype, suggesting that Her-2 expression status might play an important role, especially when both hormone receptor and Her-2 were negative.

Comparing with other three subtypes, HR-/Her-2- IMPC had more aggressive behaviors, for it had larger tumor size and more advanced histological grade and stage. Tumors which performed more aggressively were more possible to receive surgery, chemotherapy and radiotherapy. And further analysis showed that HR-/Her-2- and HR+/Her-2 + subtype had more proportions to receive mastectomy than HR+/Her-2- subtype, this was might because that HR+/Her-2- status IMPC had better biological behaviors.

We conducted a nomogram models to predict 3-year survival rate of IMPC. This tool allowed us to estimate patients' survival according to individual characteristics. For instance, a HR-/Her-2- IMPC patient who was at 50-year-old, black ethnicity, T4N3M1 stage, receiving surgery and adjuvant therapy, the 3-year overall survival rate was only $50 \%$ while at the same condition, 3-year overall survival rate of HR+/Her-2- subtype could reach to about $92 \%$. From this model, we could find that at the same background, chemotherapy and radiotherapy had smaller influence on CSS than on OS. This model made it more clear for clinical doctors to assess survival rate of IMPC patients, particularly evaluating survival rate of different subtype IMPC, thus to help doctors to make more accurate and valuable treatments strategies. 
However, this study did not obtain data on specific chemotherapy regimens which might affect prognosis. And we could not obtain data about whether Her-2 positive patients received targeted therapy (Herceptin) or not. Because the patients with Her-2 expression information only started from 2010, we selected breast cancer patients from 2010 to 2015, which might lead to insufficient follow-up time. It is necessary to follow up longer time to verify our findings. When typing breast cancer, the factor of $\mathrm{Ki}-67$ is lacking, a factor that is practical for most breast cancers. And it would be better to acquire data about local recurrence rate (LRR), recurrence-free interinterval (RFI) and distant relapse-free survival (DRFS) data to make a more complete analysis of the four subtypes of IMPC.

\section{Conclusion}

This population-based study provided evidence that HR-/Her-2- IMPC accounted the smallest part of four subtypes, but were more likely to have larger tumor size and more advanced histological grade. Furthermore, HR+/Her-2- IMPC had most unfavorable prognosis among four subtypes.

\section{Abbreviations}

IMPC: invasive micropapillary carcinoma; IDC: invasive ductal carcinoma; OS: overall survival; CSS: cancer-specific survival; HR: hormone receptor; ER: estrogen receptor; HER2: human epidermal growth receptor 2.

\section{Declarations}

\section{Ethics approval and consent to participate:}

not applicable

\section{Consent for publication:}

The only author Yuting Sun agree to submit this manuscript.

\section{Competing Interests:}

The authors have no conflict of interest.

\section{Funding:}

not applicable

\section{Authors' contributions:}

Yuting Sun did all work to this job.

\section{Acknowledgements:}

not applicable.

Data statement: The data support the findings of this study are available from the SEER database but restriction apply to the availability of these data, which were used under license for current study, and so are not publicly available. 


\section{References}

1. Yang YL, Liu BB, Zhang X, Fu L, Invasive Micropapillary Carcinoma of the Breast: An Update, Archives of pathology \& laboratory medicine, 140 (2016) 799-805.

2. Chen AC, Paulino AC, Schwartz MR, Rodriguez AA, Bass BL, Chang JC, Teh BS. Population-based comparison of prognostic factors in invasive micropapillary and invasive ductal carcinoma of the breast. British journal of cancer. 2014;111:619-22.

3. Yu JI, Choi DH, Park W, Huh SJ, Cho EY, Lim YH, Ahn JS, Yang JH, Nam SJ. Differences in prognostic factors and patterns of failure between invasive micropapillary carcinoma and invasive ductal carcinoma of the breast: matched case-control study. Breast. 2010;19:231-7.

4. Chen H, Wu K, Wang M, Wang F, Zhang M, Zhang P. Invasive micropapillary carcinoma of the breast has a better long-term survival than invasive ductal carcinoma of the breast in spite of its aggressive clinical presentations: a comparison based on large population database and case-control analysis. Cancer medicine. 2017;6:2775-86.

5. Chen L, Fan Y, Lang RG, Guo XJ, Sun YL, Cui LF, Liu FF, Wei J, Zhang XM, Fu L. Breast carcinoma with micropapillary features: clinicopathologic study and long-term follow-up of 100 cases. Int J Surg Pathol. 2008;16:155-63.

6. Adrada B, Arribas E, Gilcrease M, Yang WT. Invasive micropapillary carcinoma of the breast: mammographic, sonographic, and MRI features, AJR. American journal of roentgenology. 2009;193:W58-63.

7. Yu JI, Choi DH, Huh SJ, Cho EY, Kim K, Chie EK, Ha SW, Park IA, Ahn SJ, Lee JS, Shin KH, Kwon Y, Kim YB, Suh CO, Koo JS, Kim JH, Jeong BG, Kim IA, Lee JH, Park W, Differences in Prognostic Factors and Failure Patterns Between Invasive Micropapillary Carcinoma and Carcinoma With Micropapillary Component Versus Invasive Ductal Carcinoma of the Breast: Retrospective Multicenter Case-Control Study (KROG 13 - 06), Clinical breast cancer, 15 (2015) 353-361.e351-352.

8. Hao S, Zhao YY, Peng JJ, Ren F, Yang WT, Yu KD, Shao ZM. Invasive micropapillary carcinoma of the breast had no difference in prognosis compared with invasive ductal carcinoma: a propensity-matched analysis. Scientific reports. 2019;9:286.

9. Meng F, Liu B, Xie G, Song Y, Zheng X, Qian X, Li S, Jia H, Zhang X, Zhang L, Yang YL, Fu L. Amplification and overexpression of PSCA at 8q24 in invasive micropapillary carcinoma of breast. Breast cancer research treatment. 2017;166:383-92.

10. Luna-More S, Casquero S, Perez-Mellado A, Rius F, Weill B, Gornemann I. Importance of estrogen receptors for the behavior of invasive micropapillary carcinoma of the breast. Review of 68 cases with follow-up of 54 . Pathol Res Pract. 2000;196:35-9.

11. Cui LF, Guo XJ, Wei J, Liu FF, Fan Y, Lang RG, Gu F, Zhang XM, Fu L, Overexpression of TNF-alpha and TNFRII in invasive micropapillary carcinoma of the breast: clinicopathological correlations, Histopathology, 53 (2008) 381388.

12. Shi WB, Yang LJ, Hu X, Zhou J, Zhang Q, Shao ZM. Clinico-pathological features and prognosis of invasive micropapillary carcinoma compared to invasive ductal carcinoma: a population-based study from China. PloS one. 2014;9:e101390.

13. Zekioglu O, Erhan Y, Ciris M, Bayramoglu H, Ozdemir N. Invasive micropapillary carcinoma of the breast: high incidence of lymph node metastasis with extranodal extension and its immunohistochemical profile compared with invasive ductal carcinoma. Histopathology. 2004;44:18-23.

14. Badyal RK, Bal A, Das A, Singh G. Invasive Micropapillary Carcinoma of the Breast: Immunophenotypic Analysis and Role of Cell Adhesion Molecules (CD44 and E-Cadherin) in Nodal Metastasis. 24. Applied immunohistochemistry \& molecular morphology: AIMM; 2016. pp. 151-8. 
15. Kim MJ, Gong G, Joo HJ, Ahn SH, Ro JY. Immunohistochemical and clinicopathologic characteristics of invasive ductal carcinoma of breast with micropapillary carcinoma component. Arch Pathol Lab Med. 2005;129:1277-82.

16. Gokce H, Durak MG, Akin MM, Canda T, Balci P, Ellidokuz H, Demirkan B, Gorken IB, Sevinc Al, Kocdor MA, Saydam S, Harmancioglu O. Invasive micropapillary carcinoma of the breast: a clinicopathologic study of 103 cases of an unusual and highly aggressive variant of breast carcinoma. The breast journal. 2013;19:374-81.

17. Chen AC, Paulino AC, Schwartz MR, Rodriguez AA, Bass BL, Chang JC, Teh BS. Prognostic markers for invasive micropapillary carcinoma of the breast: a population-based analysis. Clin Breast Cancer. 2013;13:133-9.

18. Crispo A, Barba M, D'Aiuto G, De Laurentiis M, Grimaldi M, Rinaldo M, Caolo G, D'Aiuto M, Capasso I, Esposito E, Amore A, Di Bonito M, Botti G, Montella M. Molecular profiles of screen detected vs. symptomatic breast cancer and their impact on survival: results from a clinical series. BMC Cancer. 2013;13:15.

19. Engstrom MJ, Opdahl S, Hagen Al, Romundstad PR, Akslen LA, Haugen OA, Vatten LJ, Bofin AM. Molecular subtypes, histopathological grade and survival in a historic cohort of breast cancer patients. Breast cancer research treatment. 2013;140:463-73.

20. Vaz-Luis I, Ottesen RA, Hughes ME, Marcom PK, Moy B, Rugo HS, Theriault RL, Wilson J, Niland JC, Weeks JC, Lin $\mathrm{NU}$. Impact of hormone receptor status on patterns of recurrence and clinical outcomes among patients with human epidermal growth factor-2-positive breast cancer in the National Comprehensive Cancer Network: a prospective cohort study. 14. Breast cancer research: BCR; 2012. p. R129.

21. Pettinato G, Manivel CJ, Panico L, Sparano L, Petrella G. Invasive micropapillary carcinoma of the breast: clinicopathologic study of 62 cases of a poorly recognized variant with highly aggressive behavior. Am J Clin Pathol. 2004;121:857-66.

22. Abubakar M, Sung H, Bcr D, Guida J, Tang TS, Pfeiffer RM, Yang XR. Breast cancer risk factors, survival and recurrence, and tumor molecular subtype: analysis of 3012 women from an indigenous Asian population. 20. Breast cancer research: BCR; 2018. p. 114.

23. Tamimi RM, Colditz GA, Hazra A, Baer HJ, Hankinson SE, Rosner B, Marotti J, Connolly JL, Schnitt SJ, Collins LC. Traditional breast cancer risk factors in relation to molecular subtypes of breast cancer. Breast cancer research treatment. 2012;131:159-67.

\section{Figures}


Points

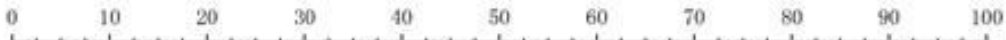

Age

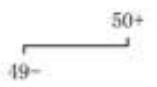

Ethnicity

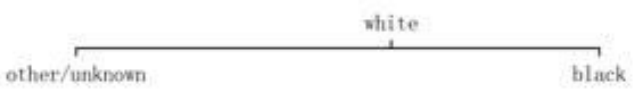

T stage

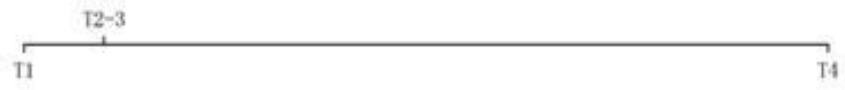

N stage

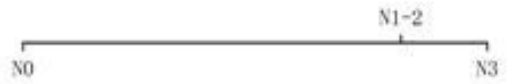

MI

M stage

10

Surgery type

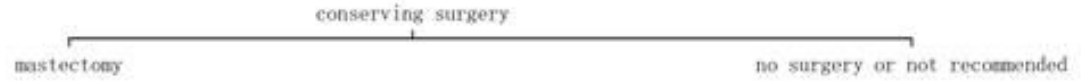

Radiotherapy

no/ unknown

Chenotherapy

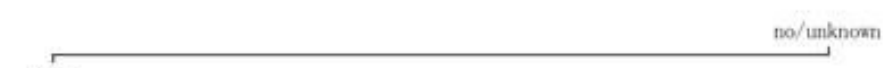

no/unknown

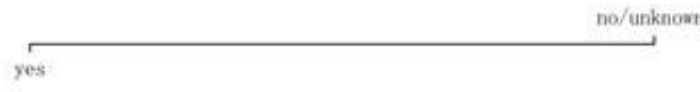

Subtype

$\mathrm{HR}-/ \mathrm{Her}-2+$

HR-/ller-2-

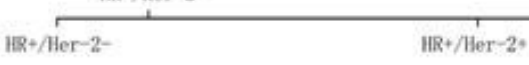

Total Points

\begin{tabular}{llllllllllll}
\hline 0 & 50 & 100 & 150 & 200 & 250 & 300 & 350 & 400 & 450 & 500 & 550
\end{tabular}

3-year survival probability

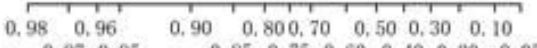

$\begin{array}{lllllllllllll}0.97 & 0.95 & 0.85 & 0.75 & 0.60 & 0.40 & 0.20 & 0.05\end{array}$

Figure 1

3-year overall survival nomogram models of IMPC patients. 
Points

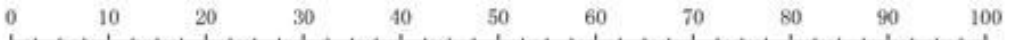

Age

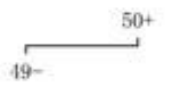

Ethnicity

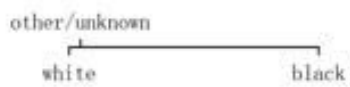

T stage

$12-3$

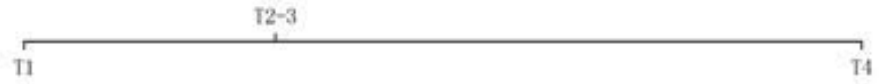

$\mathrm{N}$ stage

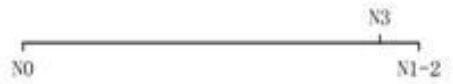

M stage

MI

Surgery type

no

Surgery type

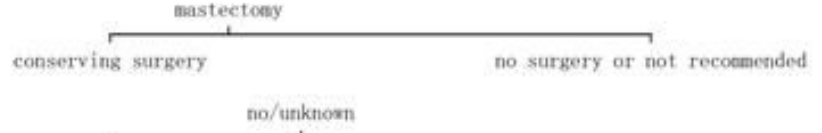

Radiaotherapy

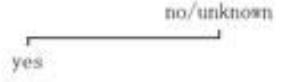

Chenotherapy

no/ unknown

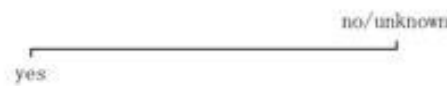

Subtype

$\mathrm{UR}+/$ Her-2-

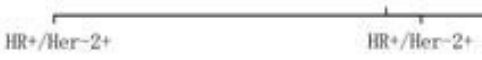

IIR-/Ber-2-

Total Points

\begin{tabular}{lllllll}
\hline 0 & 100 & 150 & 200 & 250 & 300 & 350
\end{tabular}

3-year survival probability

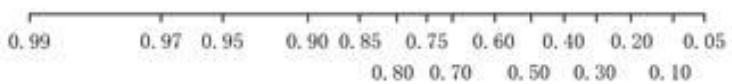

\section{Figure 2}

3-year overall survival nomogram models of IMPC patients. 


\section{Overall survival of four subtypes}

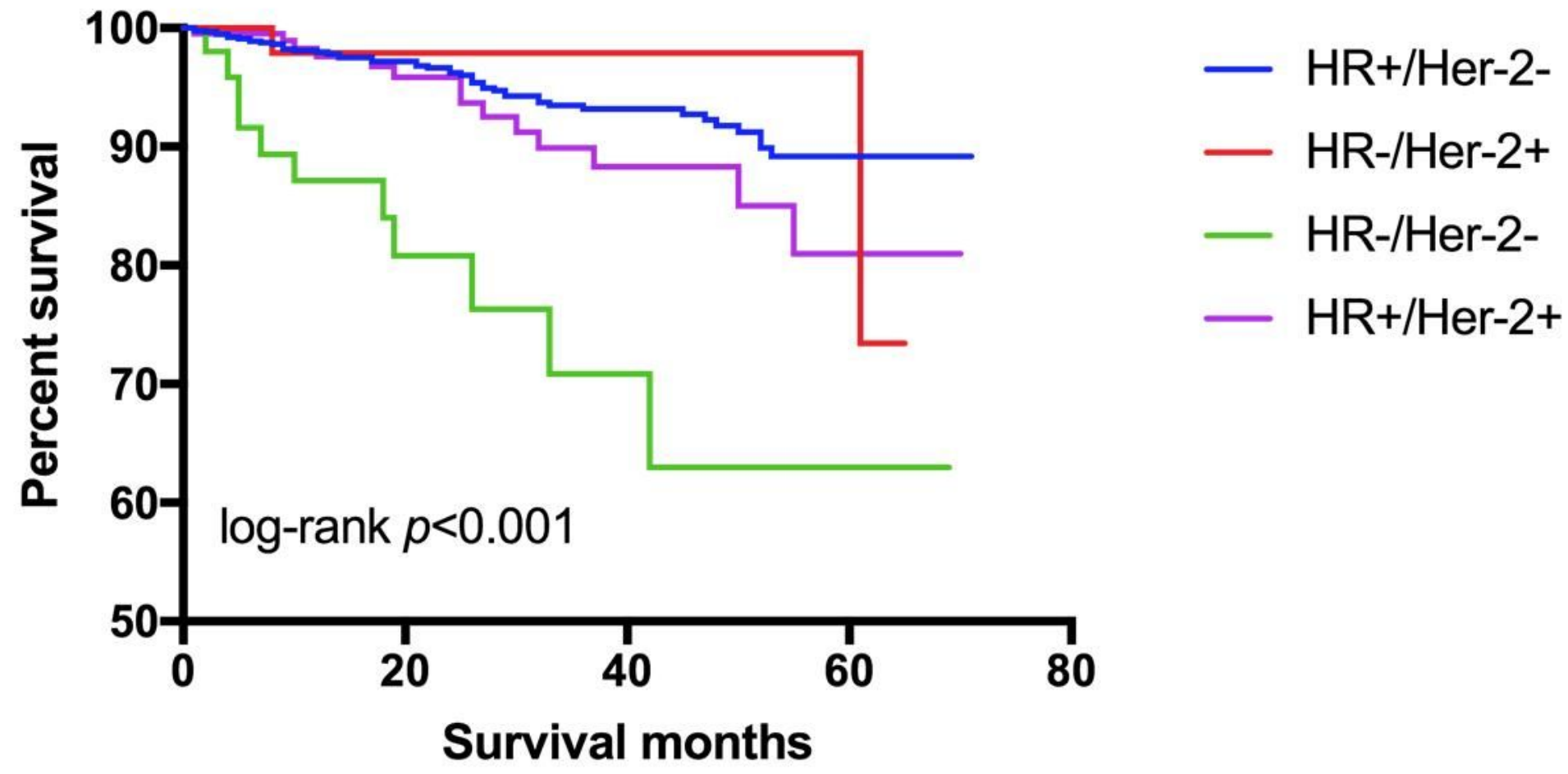

Figure 3

Overall survival of four subtypes IMPC patients. Log-rank test was used to verify $p$ value, and $p<0.05$ means statistically significant.

\section{Cancer-specific survival of four subtypes}

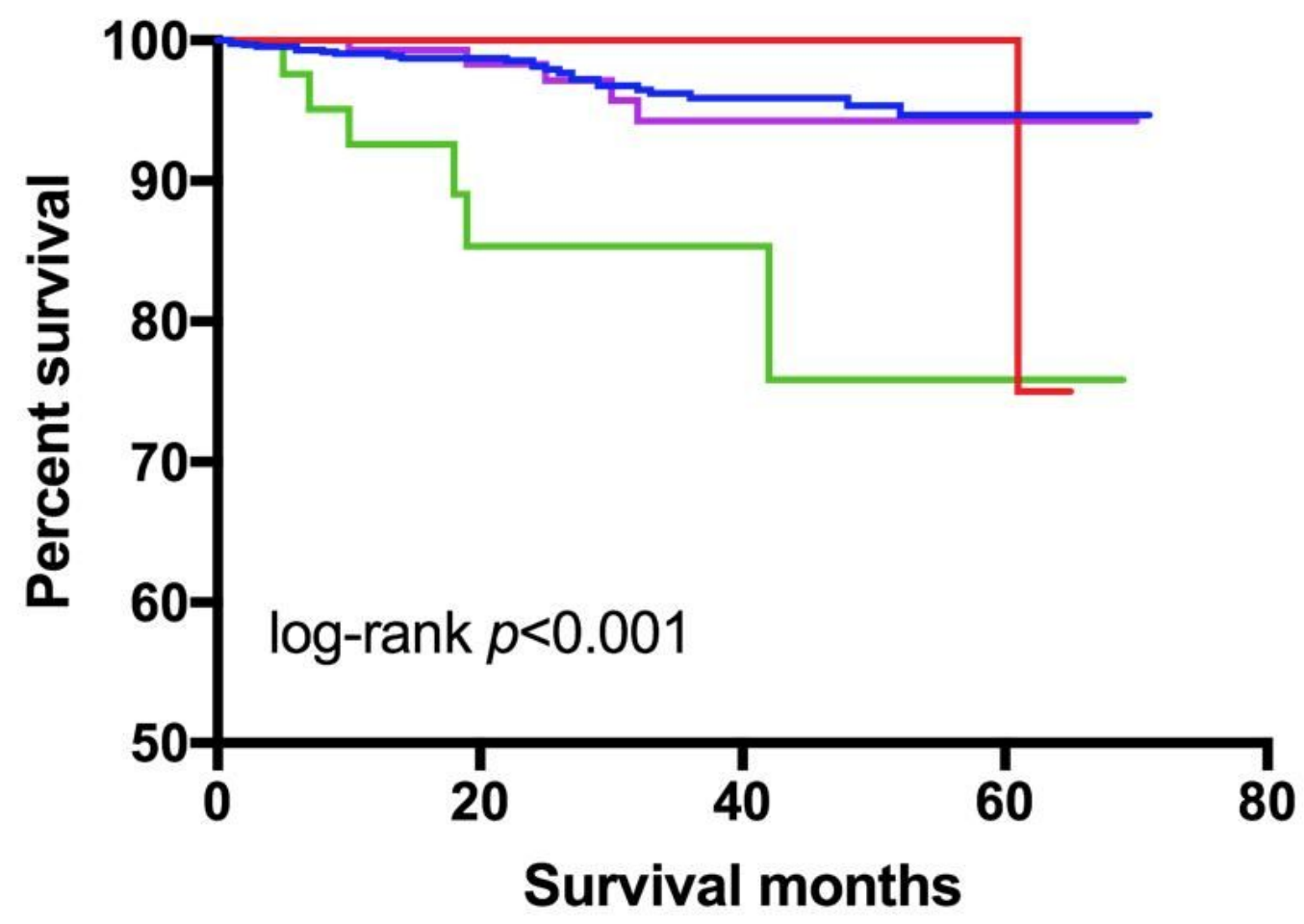

- HR+/Her-2-

- HR-/Her-2+

- HR-/Her-2-

- HR+/Her-2- 


\section{Figure 4}

cancer-specific survival of four subtypes IMPC patients. Log-rank test was used to verify $p$ value, and $p<0.05$ means statistically significant.

\section{Supplementary Files}

This is a list of supplementary files associated with this preprint. Click to download.

- supplementaryfigure2.tif

- supplementaryfigure1.tif 